\title{
Investigating the Impact of Prenatal Training on Anxiety Sensitivity and Control in Stress-prone Pregnant Women
}

\section{Sara Amouzandeh ${ }^{1 *}$, Mojgan Agah Heris ${ }^{1}$ and Gholam Hossein Javanmard $^{2}$}

${ }^{1}$ Departments of Psychology in Payam Noor University (PNU) Garmsar Branch, Iran

${ }^{2}$ Professor, Departments of Psychology in Payam Noor University (PNU) Tehran Branch, Iran

*Corresponding Author: Sara Amouzandeh, Departments of Psychology in Payam Noor University (PNU) Garmsar Branch, Iran
Received: November 08, 2021

Published: December 31, 2021

(C) All rights are reserved by Sara

Amouzandeh., et al.

\begin{abstract}
The purpose of this study is to investigate the effectiveness of prenatal training on modulating anxiety sensitivity and anxiety control perception in stress-prone pregnant women. A quasi-experimental study was conducted on 125 volunteers by convenience sampling method and 40 persons were randomly selected and divided into two groups (experimental/control). Each individual has answered the pregnancy anxiety, anxiety control perception and anxiety sensitivity questionnaires before and after training. During the training, experimental techniques and healthy lifestyle were taught during 8 sessions of 120 minutes. Experimental results, with Cronbach's alpha higher than 0.92, indicate that stress management training combined with healthy lifestyle techniques increased anxiety control perception ( $\mathrm{p}<0.05$ ), while decreasing perceived stress and pregnancy anxiety in stress-prone pregnant women ( $\mathrm{p}$ $<0.05$ ). Moreover, the results show that psychological training during pregnancy, such as relaxation and healthy lifestyle, reduces pregnancy anxiety, perceived stress and increases anxiety control perception in pregnant women prone to stress.
\end{abstract}

Keywords: Gestational Anxiety; Anxiety Control Perception; Anxiety Sensitivity; Stress

\section{Introduction}

Despite the fact that pregnancy can create a passion and enthusiasm, it is one of the most stressful periods in a woman's life. Gestational anxiety refers to one's concerns, occupations, and fears regarding pregnancy, childbirth, infant health, and future parenting [1]. Stress during pregnancy is categorized as episodic (e.g., life events, disasters and daily unrest), chronic or emotional states of depression. Women respond to each type of stress in different way. Stress can cause labor pains due to release of catechol amines and myometrial dysfunction, leading to ineffective and prolonged pain
[2,3]. On the other hand, fear and anxiety can lead to more blood flowing to the body organs involving the immune response, such as the brain, heart, muscles, hands, feet, and upper body, which results in lower blood pressure in other organs, including the uterus [4]. As a result, the fetus receives less oxygen and nutrients.

Studies have shown that anxiety sensitivity is an important vulnerability factor in development and persistence of mental disorders [5]. Individuals with high anxiety sensitivity interpret emotions such as rapid heart rate, sweating and confusion as a sign of heart attack, social shame, and mental instability [6]. Thus, there 
is a faulty cycle between physical emotions, evaluations, negative interpretation, and anxiety. Such faulty cycle constantly and permanently puts the person in a state of alarm over the physical symptoms of anxiety [7-9]. Perceived stress is also a psychological state or process in which a person perceives his or her physical and psychological well-being as threatening [10].

Previous studies provide evidence that stress management training is effective and important in society, especially on pregnant women (as they are directly involved in future generation's mental and physical health) that are vulnerable regarding social conflicts [11]. Note that prenatal lifestyle has long-lasting effects on maternal and child health [12]. Evidence suggests that psychological therapies and maintaining a healthy lifestyle in pregnancy will reduce the risk of adverse pregnancy complications, such as anxiety, preeclampsia, eclampsia, and premature birth $[13,14]$. The relaxation vaccination method against future stressors employs stress management techniques by increasing individuals' resistance to stressful events [15-17].

The type of coping the mother chooses to deal with stress is highly related to the stage of pregnancy. The occurrence of stress in the early months or weeks of pregnancy has more complications in the fetus [18]. Recent research has shown that even problems associated with neonatal attachment and developmental disorders such as movement and malnutrition of the baby (and eventually metabolic disorders) can be the result of severe anxiety during pregnancy and postpartum. In the current situation, where the policies of the Ministry of Health and Medical Education in many countries, such as Iran, have been changed to increase population, it is necessary to pay more attention to psychological training interventions to improve the mental health of pregnant women and as the result, future generations general health. Lack of knowledge regarding how to cope with the potential problems caused by stress can lead to injuries that sometimes affect the mother for many years after childbirth and degrade quality of life [19].

Studies show that regular physical activity during the first six months of pregnancy reduces the incidence of cesarean section and shortens the second stage of labor [20]. It also improves blood circulation in the lower limbs and, therefore preventing deep vein thrombosis in pregnancy [21]. According to the WHO recommendation, healthy pregnant women should have at least 150 minutes of moderate-intensity physical activity per week. The relaxation is a behavioral tool known as sedative. This new approach is probably the core of treatment for anxiety and mental stress; a sequential approach that has been internalized by practice [14,19]. Relaxation techniques are one of the physiological mechanisms by connecting mind and body. Thus, these techniques can have a positive effect on stress management in physical, psychological and social dimensions of general health during anxiety.

The relaxation is one of the widely used techniques in research that relieves stress and is based on learning to sense and control muscle tension. This ultimately leads to a decrease in heart rate and blood pressure after practice [22,23]. Therefore, by intervening to promote the lifestyle of pregnant women and teaching them stress management (mostly stress relief and healthy lifestyle), this study began with the hope that it would serve to promote community health.

\section{Methods}

\section{The statistical population of the study}

In order to provide an applied research experiment, we employ Quasi-experimental data collection followed by two groups of experimental and control in two states of pre-test and post-test. All of the women have completed prenatal care records in the clinics of "Shahid Akbarabadi" and "Shahid Lolagar" hospitals in Tehran, Iran during winter and spring of 2019. (Grant number: IR.PNU. REC.1397.048).

Potential participants were initially screened via Perceived Stress Scale (PSS) questionnaire for determining the eligibility. The threshold score of 28 and above was set for final eligibility via three questionnaires:1) The Anxiety Sensitivity (ASI-3) Questionnaire, 2) The Revised Anxiety Control (ACQ-R) Questionnaire, and 3) The Pregnancy Related Anxiety Questionnaire (PRAQ) according to [24]. Overall, the summary of eligibility criteria at screening process was as follows: (a) 14 to 27 weeks of gestation at the start of the study intervention, (b) age range in 20-40 years, (c) Iranian nationality, (d) elevated anxiety symptoms as determined by score of 28 or above in PSS, (e) No use of any special pregnancy-related drug during examination, (f) single pregnancy, (g) willing and able to participate in eight sessions of Stress relief and healthy lifestyle (SRHL) Pregnancy intervention.

Based on the available sampling method, inclusion and exclusion criteria of 125 person responded to the 14-item Perceived 
Stress Questionnaire (PSQ). Exactly 40 subjects scored 28 and above, which is identified as high-stress. At the beginning of work, the pregnancy of two patients (one due to preterm labor and the other one with a diagnosis of fetal abnormality) have ended. Therefore, the experiments were held based on a group of 38 pregnant women recruited from the prenatal clinics of the Shahid AkbarAbadi and Shahid Lolagar hospitals. Participants were randomly divided into two 19-member groups.

\section{Measurement tools}

Each participant answered all items of the selected questionnaires, such as ASI-3, ACQ-R and the Wendenberg's pregnancyrelated anxiety/fear questionnaire. In the followings, we provide a brief description regarding employed questionnaires.

- $\quad$ Perceived stress questionnaire (PSS): Proposed by Cohen., et al. [24], is a world-wide scale to measure perceived stress. The questionnaire has 4, 10 and 14-item versions. In this study we employed the most complete version (14-item) to measure general stress during the past month. This questionnaire measures thoughts and feelings about stressful events, controlling, overcoming and coping with new and/or previously experienced stress. This questionnaire has been widely used in different countries and therefore, has been translated into various languages and been standardized for many countries. A study [25] confirmed the validity and reliability of this questionnaire through exploratory and confirmatory factor analysis. In a study aimed at psychometric analysis of the perceived stress scale among a group of Chinese women, the internal consistency coefficient of PSS was obtained using Cronbach's alpha of 0.86 [26]. The 14-item questionnaire consists of 7 negative items indicating the inability to cope with stress and 7 positive items indicating good compliance with stressors. Each negative item has a 5-point Likert scale: (0) never, (1) almost never, (2) sometimes, (3) often, and (4) often. Note that the positive items have inverse scoring. Higher final scores indicate higher perceived stress [27]. Internal consistency reliability coefficients of the scale have been obtained by previous work through Cronbach's alpha in the range of $84 \%$ to $86 \%$ in different scenarios. As a result, depression and physical wellbeing are associated with health services, anxiety, and low life satisfaction [24].
- The ASI-3 questionnaire: Is a self-report questionnaire with 18 items [28]. The two-dimensional index was first constructed by [29] with 16 items. Due to the limitations of the original ASI, its revision resulted in the formulation of the ASI-3 with 18 items. Generally, the anxiety susceptibility index has a multidimensional structure with one high-order factor and three lower-order factors $[30,31]$. The primary questionnaire structure consists of three factors: (i) fear of physical worry (8 questions: 4, 6, 8, 9, 10,11,14,15), (ii) fear of not having cognitive control (4 questions: $2,5,12,16$ ), (iii) and social anxiety (4 questions: 1, 3, 7, 13) [32]. The highest score a person can get is 80 and the lowest one is 16 . Higher scores indicate higher susceptibility to anxiety. Re-test validity after two weeks of 0.75 and 0.71 after three years has shown that anxiety susceptibility index is a stable personality construct [33]. Birami., et al. investigated the psychometric properties of this questionnaire and its validity was calculated based on three methods of internal consistency, test-retest and quasivalidity, which were $0.93,0.95$ and 0.97 for the entire scale, respectively [34]. Another study [35], conducted in two college samples showing very high internal reliability (95-94\%) for the anxiety susceptibility index [36].

- Revised Anxiety Control (ACQ-R) Questionnaire: Is designed to test individuals' perception of controlling emotional reactions and external threats [37]. Rapee., et al. showed that perceived anxiety control is correlated with anxiety, depression, and stress in different samples of anxiety clinic patients, undergraduate students, and erectile dysfunction patients. The first 58 items of the questionnaire were reduced to 30 after review. Each item has five answers examining four indicators: 1 ) no external control, 2) internal control, 3) no internal control, and 4) effective coping. A score is set from "strongly disagree $=$ score 0 " to "strongly agree $=$ score 5 " on Likert scale. Higher scores indicate a greater degree of perception of control over anxious events. The latent variable of control perception was created using three subscales (Emotion Control, Threat Control, Stress Control) resulting the ACQ-R Questionnaire as an indicator [38]. This questionnaire has been validated based on different samples and has good internal consistency and testretest reliability [38]. 
- Pregnancy Related Anxiety Questionnaire (PRAQ): Measures pregnancy fears/concerns and was developed in 1989 [39]. The PRAQ questionnaire has 58 items. PRAQ contains five factors in its analysis: (1) stress of childbirth (14 items), (2) fear of having a physically or mentally disabled child (5 items), (3) fear of change in marital relationships (13 items), (4) fear of change Mood and its effects on the child (16 articles), and (5) self-centered fears or fear of changes in the mother's personal life ( 7 articles). All substances had a factor load higher than 0.3. It is worth mentioning that the last three questions are general cases that represent a general picture of pregnancy and are not included in the analysis. The score of each item is denoted from zero to seven. The final pregnancy anxiety score can range between zero and 406 [40]. In a study by Huizink., et al. PRAQ scored a high Cronbach's alpha for all subscales 0.76 throughout pregnancy. Moreover, the Cronbach's alpha for each of the components during pregnancy was calculated as follows: 0.47 for fear of childbirth, 0.41 for stress to birth physically and mentally disabled, 0.65 for anxiety about marital relationship change, 0.66 for anxiety about mood changes, 0.51 for self-centered emotions or fear of changes, and 0.81 for the whole scale.

Training details of experimental group

We planned a total of 8 sessions (each having duration about 120 minutes) to provide stress-relieving and healthy-lifestyle trainings only for experimental group. Each session consisted of two parts: 1) theory and 2) practice. The first part of the session mainly was focused on stress management techniques, while the second part was regarding relaxation techniques. In addition, members of both groups benefited from routine training in the Pregnancy control clinic.

The general overview of each planned session is described as follows:

- $\quad$ First session: Started with providing a general introduction of the program and participants to each other. Moreover, the participants were taught the benefits of teamwork and encouraged to participate in the group sessions. The rest of the session was mainly focused on general information regarding: biological clock, advice and emphasis on daily activities, the nervous system and the regulation of internal hormones, stress, and abdominal breathing training. Finally, the participants were asked to express their feelings about the pregnancy and the session.

- $\quad$ Second session: This session was mainly focused on healthy sleep techniques. After a summary of previous session and group rehearsal, following subjects were discussed: Sleep Health (REM and NREM sleep stages), Bed time and half day sleep, Benson's method of relaxation training, and some final advices regarding healthy sleep routines.

- Third session: After a quick summary of the previous session, following subjects were introduced to participants: Pregnancy physiology and relationship of placenta, fetus and mother, risk of starting diabetes, thyroid problems and pregnancy poisoning. Relaxation trainings included: 1st progressive muscle relaxation (group relaxation training), health advice, and expressing the participants' feelings.

- Fourth Session: At the beginning, an overview of the previous sessions was given and participants' questions were answered. The rest of the session was mainly focused of food health by providing information regarding subjects such as healthy food, WHO recommendations, and states of the gastrointestinal tract in pregnancy. Relaxation trainings included: 2nd progressive muscle relaxation (group relaxation training), express the participants' feelings, and health advice.

- $\quad$ Fifth Session: First, different types of disturbing and ineffective thoughts were explained. Later, the participants were encouraged to self-talk and mind-reading. Later, general coping strategies were discussed, such as: SUD Thermometer (Subjective Unit of Distress), Coping Solution to monologue and dialogue, copping and writing every thought on paper, defining regret and dealing with jealousy. The right way to compare. Relaxation trainings included: 3rd progressive muscle relaxation (group relaxation training), expressing the feeling of attendees, and health tips.

- Sixth Session: After reviewing previous sessions in brief, per participant questions have been answered. The rest of the session was focused on explain the types of aggression, daring, focusing and applying the senses to control the will and imagination. Moreover, 4th progressive muscle relaxation (singlegroup) were taught. 
- $\quad$ Seventh Session: As a good stress-revealing technique, being with oneself and focusing on the whole body along with illustration and mind calm, were the focus of this session. Moreover, the session ended up with more self-contained stress control trainings and additional health advices.

- Eighth Session: As the last session, a comprehensive overview of previous sessions was given. During the rest of the session, some techniques regarding healthy behavior in pregnancy (sexual health with the partner), physical activities, relaxation and abdominal breathing during delivery were given to the participants. At the second part of the eighth session a general training on the following subjects was held: 1) how to hug the baby, 2) important breastfeeding tips, and 3) baby bathing. Later, participants answered the post-test questionnaire.

Findings

We have analyzed the findings in two folds: 1) descriptive and 2) inferential statistics.

\section{Descriptive statistics}

The experiments held on a total of 38 subjects in 2 groups (experimental and control) with the age range of 21 to 42 with the mean of 25.5 years and the standard deviation of 5.28. Table 1 presents general information regarding descriptive statistics of participants. A big portion of participants were in their first or second pregnancy. Around $37 \%$ of the fetuses were a boy. Moreover, two number of participants have failed previous pregnancy in their medical history. According to the prenatal control files, none of the participants had an underlying disease. The participants were treated only by common pregnancy supplements and multivitamins. It is worth mentioning that every participant was in the second or third trimester of pregnancy.

\section{Pregnancy anxiety}

Table 2 shows the difference of means between pre-test and post-test scores of pregnancy anxiety test divided to five sub-categories. The overall results indicate that the experimental group shows a noticeable improvement by a more than $36 \%$ decrease

\begin{tabular}{|c|c|c|c|c|c|c|c|c|c|c|c|c|}
\hline \multirow[t]{2}{*}{ Statistics } & \multicolumn{2}{|c|}{ Education } & \multicolumn{2}{|c|}{ Marital status } & \multicolumn{2}{|c|}{ Employed? } & \multicolumn{4}{|c|}{ \# of Pregnancy } & \multicolumn{2}{|c|}{ Fetus Sex } \\
\hline & Diploma (or less) & Higher Education & Married & Single & No & Yes & $1^{\text {st }}$ & $2^{\text {nd }}$ & $3^{\text {rd }}$ & $4^{\text {th }}$ & $\mathbf{M}$ & $\mathbf{F}$ \\
\hline Number & 25 & 13 & 38 & 0 & 28 & 10 & 16 & 12 & 5 & 5 & 14 & 24 \\
\hline
\end{tabular}

Table 1: General Statistics of Participants.

in the post-score pregnancy anxiety test. On the other hand, the control group faces an approximate of $24 \%$ increase in the general pregnancy anxiety. It is worth mentioning that in both tests (pre and post), the validity of results have been evaluated with a Cronbach's alpha being at least 0.92 .

\section{Anxiety sensitivity}

In terms of sensitivity of the anxiety to stress in pregnant women, we evaluated participants by both pre and post-test analysis as is shown in table 3 , with an overall score of 0.95 in Cronbach's alpha. The scores are differentiated by three sub-categories of physical, cognitive, and social concerns. In overall, experimental group show improvement by scoring about 33\% lower in post-test. However, there was a little improvement in the control group (around $7 \%$ ). The overall improvements in both groups indicate that stress relief training and healthy lifestyle sessions were helpful in lower- ing general anxiety sensitivity of pregnant women. More precisely, the most improvement of anxiety sensitivity in both groups was in physical concerns sub-category, which is mostly related to stress relief training. These result suggest that physical activities and especially stress relief training play a big role in decreasing anxiety sensitivity in pregnant women.

\section{Anxiety control perception}

Table 4 presents the anxiety control perception scores of participants for both pre and post-tests in detail. As results suggest, the experimental group show more than $20 \%$ improvement in the post-test scores, while the control group have worsened by more than $28 \%$ compared to their pre-test scores. To this end, it is clear that the experiments have strong relation with anxiety control perception. In both groups, the overall score for Cronbach's alpha is above 0.94 . 


\begin{tabular}{|c|c|c|c|c|c|c|}
\hline \multirow[t]{2}{*}{ Index } & \multirow[t]{2}{*}{ Group } & \multicolumn{2}{|c|}{ Test scores } & \multirow{2}{*}{$\begin{array}{l}\text { Difference of } \\
\text { Means }\end{array}$} & \multirow{2}{*}{$\begin{array}{c}\text { Standard De- } \\
\text { viation }\end{array}$} & \multirow[t]{2}{*}{ \# of Members } \\
\hline & & Pre. & Post. & & & \\
\hline \multirow[t]{3}{*}{ Fear of childbirth } & Exp. & 27.16 & 18.63 & -8.52 & 6.5 & 19 \\
\hline & Con. & 19.42 & 28.95 & 9.52 & 6.44 & 19 \\
\hline & Total & 23.29 & 23.79 & 0.5 & 11.15 & 38 \\
\hline \multirow{3}{*}{$\begin{array}{l}\text { Fear of giving birth to a physically } \\
\text { or mentally disabled child }\end{array}$} & Exp. & 31.21 & 18.95 & -12.26 & 7.48 & 19 \\
\hline & Con. & 24.58 & 28.53 & 3.94 & 5.33 & 19 \\
\hline & Total & 27.89 & 23.74 & -4.10 & 10.41 & 38 \\
\hline \multirow[t]{3}{*}{ Fear of change in marital relations } & Exp. & 58.21 & 38.26 & -19.94 & 10.71 & 19 \\
\hline & Con. & 45.26 & 55.05 & 9.78 & 7.8 & 19 \\
\hline & Total & 23.74 & 46.65 & -5.07 & 17.67 & 38 \\
\hline \multirow{3}{*}{$\begin{array}{l}\text { Fear of mood swings and its con- } \\
\text { sequences for the child }\end{array}$} & Exp. & 22.05 & 13.37 & -8.68 & 6.5 & 19 \\
\hline & Con. & 16.53 & 22.47 & 9.52 & 6.44 & 19 \\
\hline & Total & 19.29 & 17.92 & 0.5 & 11.15 & 38 \\
\hline \multirow{3}{*}{$\begin{array}{c}\text { Self-centered fears or fear of } \\
\text { changes in the mother's personal } \\
\text { life }\end{array}$} & Exp. & 30.53 & 27.89 & -11.63 & 7.84 & 19 \\
\hline & Con. & 24.21 & 18.89 & 3.4 & 3.68 & 19 \\
\hline & Total & 27.37 & 23.39 & 9.78 & -3.97 & 38 \\
\hline \multirow[t]{3}{*}{ Overall } & Exp. & 169.16 & 108.11 & -61.05 & 31.68 & 19 \\
\hline & Con. & 130 & 162.89 & 32.89 & 20.21 & 19 \\
\hline & Total & 149.58 & 135.5 & -14.07 & 54.34 & 38 \\
\hline
\end{tabular}

Table 2: Pregnancy Anxiety Pre and Post Scores.

\begin{tabular}{|c|c|c|c|c|c|c|}
\hline \multirow[t]{2}{*}{ Index } & \multirow[t]{2}{*}{ group } & \multicolumn{2}{|c|}{ Test scores } & \multirow{2}{*}{$\begin{array}{l}\text { Difference } \\
\text { of Means }\end{array}$} & \multirow{2}{*}{$\begin{array}{l}\text { Standard } \\
\text { Deviation }\end{array}$} & \multirow[t]{2}{*}{ \# of Members } \\
\hline & & Pre. & Post. & & & \\
\hline \multirow[t]{3}{*}{ Physical concern } & Exp. & 7.42 & 4.47 & -2.94 & 3.4 & 19 \\
\hline & Con. & 12.53 & 9.58 & -2.94 & 6.66 & 19 \\
\hline & Total & 9.98 & 7.03 & -2.94 & 5.21 & 38 \\
\hline \multirow[t]{3}{*}{ Cognitive concern } & Exp. & 4.95 & 3.11 & -1.84 & 2.79 & 19 \\
\hline & Con. & 6.68 & 7.42 & 0.73 & 6.23 & 19 \\
\hline & Total & 5.82 & 5.27 & -0.55 & 4.94 & 38 \\
\hline \multirow[t]{3}{*}{ Social concern } & Exp. & 8.63 & 6.21 & -2.42 & 2.87 & 19 \\
\hline & Con. & 9.37 & 9.42 & 0.05 & 6.83 & 19 \\
\hline & Total & 9 & 7.82 & -1.18 & 5.32 & 38 \\
\hline \multirow[t]{3}{*}{ Overall } & Exp. & 21 & 13.79 & -7.21 & 6.81 & 19 \\
\hline & Con. & 28.58 & 26.42 & -2.15 & 17.87 & 19 \\
\hline & Total & 24.79 & 20.11 & -4.68 & 13.58 & 38 \\
\hline
\end{tabular}

Table 3: Anxiety Sensitivity of Pregnant Women. 


\begin{tabular}{|c|c|c|c|c|c|c|}
\hline \multirow[t]{2}{*}{ Index } & \multirow[t]{2}{*}{ Group } & \multicolumn{2}{|c|}{ Test scores } & \multirow{2}{*}{$\begin{array}{l}\text { Difference of } \\
\text { Means }\end{array}$} & \multirow{2}{*}{$\begin{array}{l}\text { Standard } \\
\text { Deviation }\end{array}$} & \multirow{2}{*}{$\begin{array}{c}\text { \# of Mem- } \\
\text { bers }\end{array}$} \\
\hline & & Pre. & Post. & & & \\
\hline \multirow[t]{3}{*}{ Emotional control } & Exp. & 11.05 & 14.79 & 3.73 & 2.55 & 19 \\
\hline & Con. & 8.05 & 5.42 & -2.63 & 3.89 & 19 \\
\hline & Total & 9.55 & 10.1 & 0.55 & 4.57 & 38 \\
\hline \multirow[t]{3}{*}{ String control } & Exp. & 13.58 & 15.47 & 1.89 & 1.85 & 19 \\
\hline & Con. & 11.47 & 9.53 & -2.21 & 2.37 & 19 \\
\hline & Total & 12.53 & 12.5 & 0.15 & 2.95 & 38 \\
\hline \multirow[t]{3}{*}{ Stress control } & Exp. & 9.95 & 12.21 & 2.26 & 2.02 & 19 \\
\hline & Con. & 6.16 & 3.58 & -2.27 & 2.98 & 19 \\
\hline & Total & 8.06 & 8.21 & 0.15 & 3.51 & 38 \\
\hline \multirow[t]{3}{*}{ Overall } & Exp. & 73.16 & 88.53 & 15.36 & 8.73 & 19 \\
\hline & Con. & 56.95 & 41 & -15.94 & 12.24 & 19 \\
\hline & Total & 65.06 & 64.78 & -0.28 & 19.02 & 38 \\
\hline
\end{tabular}

Table 4: Anxiety Control Perception in Pregnant Women.

Perceived stress

Table 5 provides detailed results of standard perceived stress test of the two groups of experimental and control. As is shown in the results, the experimental group shows improvements decreas- ing the post-test score by $6.6 \%$. However, the control group developed more perceived stress with up to $36.5 \%$ higher score in the post-test.

\begin{tabular}{|c|c|c|c|c|c|c|}
\hline \multirow{2}{*}{ Index } & \multirow{2}{*}{ Group } & \multicolumn{2}{|c|}{ Test scores } & Difference of & Standard & \# of Mem- \\
Means & Deviation & bers \\
\cline { 3 - 7 } & & Pre. & Post. & & 1.91 & 19 \\
\hline \multirow{2}{*}{ Overall } & Exp. & 27.74 & 25.89 & -1.84 & 7.68 & 19 \\
\cline { 2 - 7 } & Con. & 26.05 & 35.58 & 9.52 & 8.58 & 38 \\
\cline { 2 - 7 } & Total & 26.89 & 30.74 & 3.84 & & \\
\hline
\end{tabular}

Table 5: Perceived Stress in Participants.

\section{Inferential statistics}

To derive facts and more helpful statistics of the observations, we provide different analysis, such as one way and multi way analysis of variance, Kolmogorov-Smirnov to check the normality of data distribution, and Levon's test to evaluate the homogeneity between experimental and control groups. In overall, the input data was classified as normal distribution with homogeneous variance $(\mathrm{P}>$ 0.05).

\section{Pregnancy anxiety}

The results of the Kolmogram-Smirnov test indicate that the distribution of the total score in pregnancy anxiety tests is normal. table 6 provides detailed information of one-way analysis of variance (ANOVA) test indicating significant improvement in overall score of the pregnancy anxiety. Moreover, table 7 presents the multivariate analysis of variants (MANOVA) test for all five pregnancy anxiety sub-scales. Due to stress relieving and lifestyle trainings during pregnancy in the experimental group, we observe a significant reduction in all of the subscales in pregnancy anxiety compared to the control group. These results indicate the effectiveness of such trainings in reducing pregnancy anxiety. In addition, fear of childbirth and mood changes have significant effect on the fear of changes in mother's personal life. Finally, table 8 shows the results of the Pillai test on the effects of psychological trainings on the interaction of pregnancy anxiety subscales. 


\begin{tabular}{|c|c|c|c|c|c|}
\hline $\begin{array}{c}\text { Source of } \\
\text { changes }\end{array}$ & SS & DF & MS & F & $\begin{array}{c}\text { Meaning- } \\
\text { ful level }\end{array}$ \\
\hline Group & 83848.02 & 1 & 83848.02 & 118.74 & 0.0001 \\
\hline Error & 25420.73 & 36 & 706.13 & - & - \\
\hline Total & 116801 & 38 & - & - & - \\
\hline
\end{tabular}

Table 6: One-Way Analysis of Variance (ANOVA) Test of Pregnancy Anxiety.

\section{Anxiety sensitivity}

As same as previous tests, the results of the KolmogramSmirnov test indicate that the distribution of the total score is normal. ANOVA test (Table 9) analyzes the effectiveness of the SRLT on the sensitivity to anxiety in pregnant women prone to stress with $\mathrm{P}<0.05$. The results of Leven test showed that the variance of the experimental and control groups in the scores of subscales of anxi-

\begin{tabular}{|c|c|c|c|c|c|c|}
\hline $\begin{array}{l}\text { Source of } \\
\text { changes }\end{array}$ & The dependent variable & SS & $\begin{array}{l}\text { Degrees of } \\
\text { freedom }\end{array}$ & MS & $\mathbf{F}$ & $\begin{array}{c}\text { Significance } \\
\text { level }\end{array}$ \\
\hline \multirow[t]{5}{*}{ Group } & Fear of childbirth & 3096.02 & 1 & 3096.02 & 73.93 & 0.0001 \\
\hline & Fear of giving birth to disabled & 2496.42 & 1 & 2496.42 & 59.1 & 0.0001 \\
\hline & Fear of change in marital relations & 8400.65 & 1 & 8400.65 & 95.7 & 0.0001 \\
\hline & Fear of mood change & 2033.78 & 1 & 2033.78 & 107.5 & 0.0001 \\
\hline & fear of changes in the personal life & 2228.44 & 1 & 2228.44 & 60.93 & 0.0001 \\
\hline \multirow[t]{5}{*}{ Error } & Fear of childbirth & 1507.47 & 36 & 41.87 & - & - \\
\hline & Fear of giving birth to disabled & 1520.63 & 36 & 42.24 & - & - \\
\hline & Fear of change in marital relations & 3160.10 & 36 & 87.78 & - & - \\
\hline & Fear of mood change & 681.05 & 36 & 18.91 & - & - \\
\hline & fear of changes in the personal life & 1316.52 & 36 & 36.57 & - & - \\
\hline \multirow[t]{5}{*}{ Total } & Fear of childbirth & 4613 & 38 & - & - & - \\
\hline & Fear of giving birth disabled & 4674 & 38 & - & - & - \\
\hline & Fear of change in marital relations & 12541 & 38 & - & - & - \\
\hline & Fear of mood change & 2786 & 38 & - & - & - \\
\hline & fear of changes in the personal life & & & - & - & - \\
\hline
\end{tabular}

Table 7: Multivariate Analysis of Variants (MANOVA) Test of Pregnancy Anxiety Sub-Scales.

\begin{tabular}{|c|c|c|c|c|c|c|}
\hline \multicolumn{2}{|c|}{ Effect } & Value & F & df1 & df2 & $\begin{array}{c}\text { Significance } \\
\text { level }\end{array}$ \\
\hline Group & $\begin{array}{c}\text { Pillai } \\
\text { rejection }\end{array}$ & $0 / 57$ & $8 / 74$ & 5 & 32 & $0 / 0001$ \\
\hline
\end{tabular}

Table 8: Pillai's Test on the Effects of Psychological Trainings on Pregnancy Anxiety Sub-Scales.

ety (physical, cognitive and social) and the total score of sensitivity to anxiety are homogeneous ( $\mathrm{P}>0.05)$ ). Also, the mean scores of pre-test and post-test (Table 10) in the experimental and control groups show that in the subscales of cognitive anxiety and social anxiety, the experimental group has a lower score than the control group. But in general the difference between the mean scores is not statistically significant $(\mathrm{P}>0.05)$. More detailed information can be observed in table 10 and table 11 on this subject, suggesting no significant correlation in the results.

It can be said that the SRLT program in eight sessions may have had a positive effect on participants' cognitive ability and excitement (Table 3 and Table 10) but the duration was not long enough to show itself in the behavioral feedback of pregnant women. These findings were partly in line with the findings reported by Rashid and Parish (1998) who reported a positive effect of progressive muscle relaxation on reducing anxiety, but also found its use to be ineffective in reducing trait anxiety or natural anxiety [41]. So that stress management training in primary pregnant women improves state/trait anxiety $(\mathrm{P}<0.001)$ and mental health $(\mathrm{P}<0.015)$, but 
do not reduce another aspect of pregnancy anxiety, which is the concern about changes in body appearance $(\mathrm{P}<0.12$. Moreover, it is also possible that participants in the experimental group, who underwent a relieving stress and a healthy lifestyle training, learned the desired responses or behaviors, but did not change their reactions due to the lack of reinforcement.

Bandura believes that there is a difference between learning a reaction and implementing it [42]. Subjects in the experimental group learned enough techniques and internalized them to significantly reduce the physiological and behavioral effects of anxiety, but due to lack of motivation, they did not decide to use the learned techniques. This phenomenon is also was observed in previous work such as [43]. which show that stress management training in 5 weeks for young pregnant women and pregnant adolescents significantly reduced cognitive manifestations and emotional effects of stress in the experimental group, but its consistent in physiological manifestations and the behavior was not significant compared to the control group. Taken together, these results indicate that further research with a larger sample is warranted.
On the other hand, it seems that factors such as social support, marital satisfaction, pregnant woman's age, and education affect the subscales of anxiety sensitivity. In previous studies, Glazier., et al. too have shown that there is significant relation between pregnancy anxiety and factors such as marital satisfaction, age, and education. They concluded that lower age, higher education, and higher marital satisfaction were more important in explaining the differences in pregnancy anxiety in terms of being in a particular period of pregnancy $[44,45]$. As our results from tables 11 and 12 suggest, this paper also proves such hypothesis.

\begin{tabular}{|c|c|c|c|c|c|}
\hline $\begin{array}{c}\text { Source of } \\
\text { changes }\end{array}$ & SS & Df & MS & F & $\begin{array}{c}\text { Meaningful } \\
\text { level }\end{array}$ \\
\hline Group & 242.52 & 1 & 242.52 & 1.32 & 0.25 \\
\hline Error & 6587.68 & 36 & 182.99 & - & - \\
\hline Total & 7664 & 38 & - & - & - \\
\hline
\end{tabular}

Table 9: One-Way Analysis of Variance (ANOVA) Test of Anxiety Sensitivity.

\begin{tabular}{|c|c|c|c|c|c|c|}
\hline Source of changes & The dependent variable & SS & Degree of freedom & MS & F & Meaningful level \\
\hline \multirow{3}{*}{ Group } & Physical concern &. & 1 &. &. & \\
\cline { 2 - 7 } & Cognitive concern & 63.18 & 1 & 36.18 & 2.7 & 0.1 \\
\cline { 2 - 7 } & Social concern & 58.13 & 1 & 58.13 & 2.11 & 0.15 \\
\hline \multirow{2}{*}{ Error } & Physical concern & 1007.89 & 36 & 27.99 & - & - \\
\cline { 2 - 7 } & Cognitive concern & 840.21 & 36 & 23.33 & - & - \\
\cline { 2 - 7 } & Social concern & 989.57 & 36 & 2748 & - & - \\
\hline \multirow{2}{*}{ Total } & Physical concern & 1338 & 38 & - & - & - \\
\cline { 2 - 7 } & Cognitive concern & 915 & 1101 & 38 & - & - \\
\end{tabular}

Table 10: Multivariate Analysis of Variants (MANOVA) Test of Anxiety Sensitivity.

\begin{tabular}{|c|c|c|c|c|c|c|}
\hline \multicolumn{2}{|c|}{ Effect } & Value & F & df1 & df2 & $\begin{array}{c}\text { Significance } \\
\text { level }\end{array}$ \\
\hline Group & $\begin{array}{c}\text { Pile } \\
\text { rejection }\end{array}$ & 0.12 & 1.62 & 3 & 334 & 0.2 \\
\hline
\end{tabular}

Table 11: Pillai's Test on the Effects of Psychological Trainings on Anxiety Sensitivity Sub-Scales.

\section{Anxiety control perception}

To investigate the effectiveness of SRLT on increasing the anxiety control perception of pregnant women prone to stress, we provide one-way ANOVA analysis on the overall results as shown in table 12 . The overall scores show significant improvement in the experimental group compared to control. To provide more detailed analysis, we have also evaluated results with MANOVA test in table 13. The MANOVA analysis show strong relation between SRLT and 
anxiety control perception, especially on emotional and stress control sub-scales. For further justifications, we have also provided Pillai's null-hypothesis rejection analysis in Table 14. According to Pillai's rejection, in overall, SRLT have significant effect on the anxiety control perception of pregnant women.

The programmed SRLT sessions have been modified to include different coping methods and reconstruction of threats, more discussions regarding fear of childbirth and fear of managing the behavior of the infant. Thus, it had significant impact on increasing participants' perception of anxiety control. The findings of the present study are consistent with the results of a study by Leung., et al. [46], where the demonstration of the use of delivery balls in 203 mother hospitals in Liber causes a significant reduction in stress, and an increase in women's satisfaction.

\begin{tabular}{|c|c|c|c|c|c|}
\hline $\begin{array}{c}\text { Source of } \\
\text { changes }\end{array}$ & SS & Df & MS & F & $\begin{array}{c}\text { Meaning } \\
\text { level }\end{array}$ \\
\hline Group & 9316.44 & 1 & 9316.44 & 82.41 & 0.0001 \\
\hline Error & 4069.36 & 36 & 113.03 & - & - \\
\hline Total & 13389 & 38 & -- & -- & - \\
\hline
\end{tabular}

Table 12: One-Way Analysis of Variance (ANOVA) Test of Anxiety Control Perception.

\begin{tabular}{|c|c|c|c|c|c|c|}
\hline $\begin{array}{c}\text { Source of } \\
\text { changes }\end{array}$ & dependent variable & SS & $\begin{array}{c}\text { Degrees of } \\
\text { freedom }\end{array}$ & MS & $\begin{array}{c}\text { F } \\
\text { level }\end{array}$ \\
\hline \multirow{2}{*}{ Group } & Emotional control & 385.28 & 1 & 385.28 & 35.55 & 0.0001 \\
\cline { 2 - 7 } & String control & 160.1 & 1 & 160.1 & 35.37 & 0.0001 \\
\cline { 2 - 7 } & Stress control & 222.73 & 1 & 222.73 & 34.22 & 0.0001 \\
\hline \multirow{2}{*}{ Error } & Emotional control & 390.1 & 36 & 10.83 & - & - \\
\cline { 2 - 7 } & String control & 162.94 & 36 & 4.52 & - & - \\
\cline { 2 - 7 } & Stress control & 234.31 & 36 & - & - & - \\
\hline \multirow{2}{*}{ Total } & Emotional control & 787 & 38 & - & - & - \\
\cline { 2 - 7 } & String control & 324 & 38 & - & - & - \\
\cline { 2 - 7 } & Stress control & 458 & 38 & - & - \\
\hline
\end{tabular}

Table 13: Multivariate Analysis of Variants (MANOVA) Test of Anxiety Control Perception.

\begin{tabular}{|c|c|c|c|c|c|c|}
\hline \multicolumn{2}{|c|}{ Effect } & Value & F & df1 & df2 & $\begin{array}{c}\text { Significance } \\
\text { level }\end{array}$ \\
\hline Group & $\begin{array}{c}\text { Pillai } \\
\text { rejection }\end{array}$ & 0.6 & 17.49 & 3 & 34 & 0.0001 \\
\hline
\end{tabular}

Table 14: Pillai's Test on the Effects of Psychological Trainings on Anxiety Control Perception.

\section{Perceived stress}

The mean difference of perceived stress scores for the experimental and the control group (due to SRLT in the post-test) is relatively high. Due to homogeneity of the variance of participants' scores in test, we only evaluated the results with one-way ANOVA analysis as is shown in Table 15. The experimental group showed $6.6 \%$ decrease, while the control group faced a more than $36.5 \%$ increase in the perceived stress score. Thus, the linear relation in the effectiveness of SRLT on perceived stress is obvious, as the results of ANOVA evaluation suggests. These results are consistent with the study by Bastani., et al. [47], which showed that teaching applied relaxation techniques to anxious pregnant women can reduce state anxiety as well as perceived stress.

\begin{tabular}{|c|c|c|c|c|c|}
\hline $\begin{array}{c}\text { Source of } \\
\text { changes }\end{array}$ & SS & Df & MS & F & $\begin{array}{c}\text { Significance } \\
\text { level }\end{array}$ \\
\hline Group & 1227.78 & 1 & 1227.78 & 29.52 & 0.0001 \\
\hline Error & 1497.26 & 36 & 41.59 & - & - \\
\hline Total & 3286 & 38 & - & - & - \\
\hline
\end{tabular}

Table 15: One-Way Analysis of Variance (ANOVA) Test of Perceived Stress. 


\section{Conclusion}

In this study, we evaluate the effectiveness of the prenatal training on the anxiety sensitivity and anxiety control in stress-prone pregnant women. In all of the experiments, validity of results are proved with Cronbach's alpha being at least 0.92 . The experimental results show a noticeable decrease in the mean score of pregnancy anxiety and perceived stress in the intervention group. Moreover, the average score of perception of anxiety control of the intervention group increased significantly after the stress relieving and healthy lifestyle training. These results indicate that pregnancy anxiety in prone-to-stress pregnant women is reducible with the help of psychological training. In addition, such training can increase quality of life after childbirth and during infancy because pregnant women learn different ways to confront their stress. These results are in the same direction as a study by Hamilton., et al. [48], the association of coping with maternal characteristics, stress perceptions, disposition, and social support were analyzed and showed that how can women overcome cope with stress during pregnancy and reduce their stress. Moreover, the findings of this study are consistent the results of the research by Poudevigne., et al. [49], suggesting the direct relationship between changes in physical activity and general mood during pregnancy.

Another important finding is that psychological trainings were not able to reduce sensitivity to stress in stress-prone pregnant women. On the other hand, in a study by Rashid and Parish [41], the effectiveness of muscle relaxation on reducing anxiety in high school students was analyzed and resulted in reduced state anxiety but did not affect the quality of anxiety. Therefore, it seems that with initiating the trainings in the early stages of pregnancy, mothers gain enough time to reduce stress by using learned techniques. However, one or two follow-up sessions may be required to reinforce the stress management techniques.

Another aspect of our results show that psychological training during pregnancy is effective in reducing anxiety and increasing the perception of anxiety control, as is showed in [50,51]. In another study, Beddoe., et al. [52], concluded with the effectiveness of teaching relaxation and yoga techniques on coping mechanisms, stress reduction, anxiety, depression and health promotion during pregnancy. Moreover, Cid., et al. [53], showed a positive effect of physical activity on reducing pregnancy anxiety.
Given the population growth policies aimed at achieving a younger and more dynamic society in developing countries such as Iran, paying attention to the mental health of pregnant women is at the top of the guidelines for prenatal care and pre-pregnancy counseling. It is also recommended that stress relieving and healthy lifestyle courses to be included in high school education. In addition, pregnancy training should begin early in pregnancy and planned with more complete sessions twice a week. On the other hand, in order to achieve better results, it is suggested to make telephone consultations, nutrition counseling at the beginning of pregnancy and holding stress relieving and healthy lifestyle programs in larger samples.

\section{Acknowledgement}

The authors would like to thank all those who helped in the progress of this research, as well as the officials of Shahid Akbarabadi and Shahid Lolagar hospitals.

\section{Bibliography}

1. Field T., et al. "Pregnancy anxiety and comorbid depression and anger: effects on the fetus and neonate". Depression and Anxiety 17.3 (2003): 140-151.

2. Glover V. "Maternal depression, anxiety and stress during pregnancy and child outcome; what needs to be done". Best Practice and Research Clinical Obstetrics and Gynaecology 28.1 (2014): 25-35.

3. Lowe NK and Corwin EJ. "Proposed biological linkages between obesity, stress, and inefficient uterine contractility during labor in humans". Medical Hypotheses 76.5 (2011): 755760.

4. Lewis B., et al. "The effect of exercise during pregnancy on maternal outcomes: practical implications for practice". American Journal of Lifestyle Medicine 2.5 (2008): 441-455.

5. Telch MJ., et al. "Appraisal of social concerns: A cognitive assessment instrument for social phobia". Depression and Anxiety 19.4 (2004): 217-224.

6. Cox BJ., et al. "Anxiety sensitivity and major depression: Examination of affective state dependence". Behaviour Research and Therapy 39.11 (2001): 1349-1356.

7. Beck AT and Emery G. "Anxiety disorders and phobias: A cognitive perspective". New York: Basic Books (1985). 
8. Clark DM. "A cognitive approach to panic". Behaviour Research and Therapy 24 (1986): 461-470.

9. Chambless DL., et al. "Relationship of cognitions to fear of somatic symptoms: a test of the cognitive theory of panic". Depression and Anxiety 11.1 (2000): 1-9.

10. Moderating role of experiential avoidance in the relationship between anxiety sensitivity and perceived stress, Document Type: Research Paper.

11. Mahboobeh Shirazi., et al. "Effectiveness of anxiety control training on early pregnant wowen.

12. Sword W., et al. "Women's and care providers' perspectives of quality prenatal care: a qualitative descriptive study". BMC Pregnancy and Childbirth 12.1 (2012): 1-8.

13. Gavard JA and R Artal. "Effect of exercise on pregnancy outcome”. Clinical Obstetrics and Gynecology 51.2 (2008): 467480.

14. Urech C., et al. "Effects of relaxation on psychobiological wellbeing during pregnancy: a randomized controlled trial". Psychneuroendocrinology 35.9 (2010): 1348-1355.

15. Evers KE., et al. "A randomized clinical trial of a populationand transtheoretical model-based stress-management intervention". Health Psychology 25.4 (2006): 521.

16. Bernal AL. "Overview. Preterm labour: mechanisms and management". BMC Pregnancy and Childbirth BioMed Central 7.1 (2010): S2.

17. Khodaparast S., et al. "Examining the effect of educational intervention based on self-regulation model on perceived stress in women with gestational diabetes: A clinical trial study". Koomesh 22.2 (2020): 291-300.

18. Santrock (2003-06-30): Psychology by John W. Amazon.com: Books

19. Sadok B and Saduk V. "Summary of Psychiatry Kaplan Sadvk". Ayandehsazan publish (2010): 37-42

20. Kaiser LL and Allen L. "Position of the American Dietetic association: Nutrition and lifestyle for a healthy pregnancy outcome". Journal of the American Dietetic Association 102.10 (2002): 1469-1490.

21. Yeo GS., et al. "Birth defects in Singapore: 1994-2000". Singapore medical journal 46.10 (2005): 545.
22. DiPietro JA., et al. "Fetal responses to induced maternal relaxation during pregnancy". Biological Psychology 77.1 (2008): 11-19.

23. Nickel C., et al. "Pregnant women with bronchial asthma benefit from progressive muscle relaxation: A randomized, prospective, controlled trial". Psychother Psychosom 75 (2006): 237-243.

24. Cohen S., et al. "A global measure of perceived stress". Journal of Health and Social Behavior 1 (1983): 385-396.

25. Safaei M and O Shokri. "Assessing stress in cancer patients: Factorial validity of the perceived stress scale in Iran" (2014): $13-22$.

26. Ho RT., et al. "Association of fatigue with perceived stress in Chinese women with early stage breast cancer awaiting adjuvant radiotherapy". Stress and Health 31.3 (2015): 214-221.

27. Leung DY., et al. "Threeversions of Perceived Stress Scale: validation in a sam-ple of Chinese cardiac patients who smoke". BMC Public Health 10 (2010): 513.

28. Taylor S., et al. "Robust dimensions of anxiety sensitivity: development and initial validation of the Anxiety Sensitivity Index-3". Psychological Assessment 19.2 (2007): 176.

29. Reis S and McNally RJ. "The expectancy model of fear. In: Reiss, S. and Bootzin, R.R., Editors. Theoretical issues in Behavior Therapy. New York: Academic Press (1985).

30. Wheaton MG., et al. "Dimensions of anxiety sensitivity in the anxiety disorders: Evaluation of the ASI-3". Journal of Anxiety Disorder 26.3 (2012): 401-408.

31. Poli A., et al. "Anxiety sensitivity and obsessive-compulsive symptom dimensions: Further evidence of specific relationships in a clinical sample". Personality and Individual Differences, 109 (2017): 130-136.

32. Floyd M., et al. "Anxiety sensitivity and worry". Personality and Individual Differences 38 (2005): 1223-1229.

33. Reiss S., et al. "Anxiety sensitivity, anxiety frequency and the prediction of fearfulness". Behaviour Research and Therapy 24.1 (1986): 1-8.

34. Birami M., et al. "An Investigation of anxiety sensitivity, meta worry and components of emotion regulation in students with and without social anxiety". Clinical Psychology Studies 2.8 (2012): 43-69. 
35. Deacon BJ., et al. "The Anxiety Sensitivity Index-Revised: psychometric properties and factor structure in a nonclinical sample". Behaviour Research and Therapy 41 (2003): 14271449.

36. Erozkan A. "Determining the Anxiety Sensitivity Bases of Anxiety: A Study with Undergraduate Students". Universal Journal of Educational Research 5.1 (2017): 121-128.

37. Rapee RM., et al. "Measurement of perceived control over anxiety-related events”. Behavior Therapy 27.2 (1996): 279-293.

38. Brown TA., et al. "The Structure of Perceived Emotional Control: Psychometric Properties of a Revised Anxiety Control Questionnaire”. Behavior Therapy 35.1 (2004): 75-99.

39. Van den Bergh PhD BR. "The influence of maternal emotions during pregnancy on fetal and neonatal behavior". Journal of Prenatal and Perinatal Psychology and Health 5.2 (1990): 119.

40. Huizink AC., et al. "Prenatal psychosocial and endocrinologic predictors of infant temperament". Prenatal Stress (2000): 171.

41. Rashid ZM and Parish TS. "The effects of two types of relaxation training on students' levels of anxiety". Adolescence 33 (1998): 129.

42. Bandura A. "Social-learning theory of identificatory processes". Handbook of socialization theory and research 213 (1969): 262.

43. De Anda D., et al. "Stress management for pregnant adolescents and adolescent mothers: A pilot study". Child and Adolescent Social Work Journal 7.1 (1990): 53-67.

44. Glazier RH., et al. "Stress, social support and emotional distress in a community sample of pregnant women". Journal of Psychosomatic Obstetrics and Gynecology 25 (2004): 247-255.

45. Niaz S. "Anxiety and dep-ression in pregnant women presenting in the OPD of a teaching hospital". Pakistan Journal of Medical Science 20 (2004): 117-119.

46. Leung RW., et al. "Efficacy of birth ball exercises on labour pain management". The Hong Kong Journal 19.5 (2013): 393-933.

47. Bastani F., et al. "A randomized controlled trial of the effects of applied relaxation training on reducing anxiety and perceived stress in pregnant women". Journal of Midwifery and Women's Health 50.4 (2005): e36-40.
48. Hamilton JG and Lobel M. "Types, patterns, and predictors of coping with stress during pregnancy: Examination of the Revised Prenatal Coping Inventory in a diverse sample". Journal of Psychosomatic Obstetrics and Gynecology 29.2 (2008): 97104.

49. Poudevigne MS and O'Connor PJ. "A review of physical activity patterns in pregnant women and their relationship to psychological health". Sports Medicine 36.1 (2006): 19-38.

50. Kobau R., et al. "Mental health promotion in public health: Perspectives and strategies from positive psychology". American Journal of Public Health 101.8 (2011): e1-9.

51. Kaiser LL and Allen L. "Position of the American Dietetic association: Nutrition and lifestyle for a healthy pregnancy outcome". Journal of the American Dietetic Association 102.10 (2002): 1469-1490.

52. Beddoe AE., et al. "The effects of mindfulness-based yoga during pregnancy on maternal psychological and physical distress". Journal of Obstetric, Gynecologic and Neonatal Nursing 38.3 (2009): 310-319.

53. Cid M and González M. "Potential benefits of physical activity during pregnancy for the reduction of gestational diabetes prevalence and oxidative stress". Early Human Development 94 (2016): 57-62.

54. Cohen S. "Contrasting the Hassles Scale and the Perceived Stress Scale: Who's really measuring appraised stress". American Psychologist 41.6 (1986): 716-718.

\section{Assets from publication with us}

- Prompt Acknowledgement after receiving the article

- Thorough Double blinded peer review

- Rapid Publication

- Issue of Publication Certificate

- High visibility of your Published work

Website: $\underline{w w w}$.actascientific.com/

Submit Article: www.actascientific.com/submission.php

Email us: editor@actascientific.com

Contact us: +919182824667 